\title{
Gratitude Cognitive Behavior Therapy untuk Meningkatkan Kualitas Hidup pada Perempuan dengan HIV/AIDS
}

\author{
Gratitude Cognitive Behavior to Improve Quality of Life \\ on Women Living with HIV/AIDS
}

Nanda Putri Adhiningtyas ${ }^{1}$, Muhana Sofiati Utami ${ }^{2}$

1,2Fakultas Psikologi, Universitas Gadjah Mada

\begin{abstract}
Women living with HIV/AIDS often experience physical, psychological, and social problems. They tend to feel lonely, worthless, dissatisfied with life, anguish and even desperate. Such condition can lead to low quality of life in women with HIV/AIDS. This study aimed to examine the effectiveness of Gratitude Cognitive Behavior Therapy (G-CBT) in improving the quality of life on women living with HIV/AIDS. The hypothesis of this research was G-CBT can improve the quality of life on women living with HIV/AIDS. The participants in this study were two women living with HIV/AIDS who gained HIV status from their husbands and had undergone ARV therapy. This study was conducted in groups using small-n single-case with AB-A design. The instruments used were WHOQOL-HIV BREF Scale, Indonesia's Gratitude Scale, and self-assessment sheets. Quantitative analysis with visual inspection techniques showed that G-CBT could improve the quality of life on women living with HIV/ AIDS. Descriptive analysis showed that G-CBT had positive effect on both participants, such as increasing positive feeling and patience in their lives.
\end{abstract}

Keyword: G-CBT; HIV/AIDS; quality of life

\begin{abstract}
Abstrak. Perempuan dengan HIV/AIDS (ODHA) sering kali mengalami permasalahan baik secara fisik, psikologis, dan sosial. Hal tersebut dapat membuat mereka merasa kesepian, merasa tidak berharga, tidak puas dengan kehidupannya, sering kali merasa sedih bahkan putus asa. Kondisi tersebut dapat mengarah pada rendahnya kualitas hidup. Penelitian ini bertujuan untuk menguji efektivitas Gratitude Cognitive Behavior Therapy (G-CBT) untuk meningkatkan kualitas hidup perempuan dengan HIV/AIDS. Hipotesis penelitian ini adalah GCBT dapat meningkatkan kualitas hidup perempuan dengan HIV/AIDS. Partisipan dalam penelitian ini adalah dua orang perempuan dengan HIV/AIDS yang mendapatkan status HIV dari suaminya, dan telah menjalani terapi ARV. Penelitian ini dilakukan dalam kelompok dengan menggunakan rancangan small-n tipe single case $A-B-A$. Instrumen yang digunakan adalah Skala Kualitas Hidup WHOQOL-HIV BREF, Skala Bersyukur versi Indonesia, dan lembar penilaian diri. Analisis kuantitatif dengan teknik inspeksi visual menunjukkan bahwa G-CBT dapat meningkatkan kualitas hidup perempuan dengan HIV/AIDS. Analisis deskriptif menunjukkan bahwa G-CBT memberikan efek positif pada kedua partisipan, seperti suasana hati yang lebih positif dan lebih sabar dalam hidupnya.
\end{abstract}

Kata kunci: G-CBT; HIV/AIDS; kualitas hidup

${ }^{1}$ Korespondensi mengenai artikel ini dapat dilakukan melalui nandaputri89@yahoo.com

2atau muhana@ugm.ac.id 
Di Indonesia fenomena AIDS sudah dikenal dan menjadi isu pada awal Januari 1986, yakni dengan meninggalnya pasien di RSIJ yang menjalani uji darah dengan menggunakan metode ELISA diketahui mengidap AIDS (Djoerban, 1999). Yogyakarta sendiri termasuk dalam sepuluh besar provinsi di Indonesia dengan AIDS case rate tertinggi sampai Maret 2017 (Kementerian Kesehatan Republik Indonesia, 2018).

Risiko perempuan terinfeksi HIV/AIDS dua sampai empat kali lebih besar dibandingkan dengan laki-laki. Hal ini salah satunya dikarenakan bentuk anatomi alat kelamin perempuan yang memudahkan penularan virus HIV/AIDS melalui hubungan seksual (Azza, 2010). Selain itu, kerentanan penularan HIV/AIDS pada perempuan disebabkan oleh minimnya informasi tentang hak reproduksi dan hak seksual bagi perempuan (Yulianti, 2013). Infeksi HIV pada perempuan tidak hanya karena ketidaktahuan atau ketidakpahaman tentang cara pencegahan HIV/AIDS, namun juga terjadi karena perempuan tidak memiliki kekuatan sosial dan ekonomi untuk melindungi diri mereka, sehingga terjadi ketidaksetaraan dan ketidakadilan gender (Yulianti, 2013).

HIV/AIDS pada perempuan akan menimbulkan dampak yang sangat besar baik pada aspek fisik, psikologis, sosial, maupun spiritual. Kondisi tersebut semakin berat apabila perempuan tersebut dalam kondisi hamil, melahirkan, dan mempunyai bayi (Safarina, 2012). Dampak fisik seperti perubahan berat badan dan bentuk badan, mudah lelah, hormon menjadi tidak stabil, dan gangguan reproduksi (Spiritia, 2014).
Dampak psikologis yang dihadapi seperti stres dan cemas yang dapat berpengaruh terhadap sistem imun orang dengan HIV/AIDS (ODHA). Selain itu, proses penerimaan juga akan lebih sulit pada perempuan ketika menghadapi kenyataan bahwa dirinya terinfeksi HIV, terlebih jika mereka harus berhadapan dengan perasaan dikhianati, ditinggalkan, bahkan kehilangan dukungan finansial, jika mereka datang tanpa dukungan keluarga dan situasi yang ditinggalkan (Barboza et al., 2017).

Dampak sosial yang diterima yaitu berupa stigma dan diskriminasi. Stigma yang dimaksud antara lain mereka dianggap orang yang melanggar aturan dan mempunyai perilaku menyimpang, mereka juga harus dijauhi dan sebaiknya tidak boleh keluar rumah agar tidak menularkan penyakitnya pada orang lain (Azza, 2010). Sementara dari aspek spiritual, perempuan dengan HIV/AIDS memiliki kualitas hidup yang rendah karena sebagian besar perempuan dengan HIV/AIDS masih belum dapat menerima kenyataan mengenai statusnya dan merasa bahwa Tuhan tidak adil (Rachmawati, 2013).

Kualitas hidup merupakan komponen penting dalam evaluasi kesejahteraan dan kehidupan ODHA (Hardiansyah, Amiruddin, \& Arsyad, 2014). Hal ini dikarenakan HIV/AIDS merupakan suatu kondisi kronis yang masih menjadi ancaman berat untuk kesejahteraan seseorang dan kualitas hidupnya (Brenda \& Wet, 2010). Tingginya kualitas hidup yang dimiliki akan meningkatkan semangat hidup ODHA. Sebaliknya, rendahnya kualitas hidup pasien HIV akan memengaruhi kesehatan dari pasien itu sendiri. Peningkatan kualitas hidup tidak 
hanya dapat dilakukan melalui proses penyembuhan secara fisik, namun hal yang utama adalah meningkatkan pemahaman pasien tentang penyakitnya dan mengubah orientasi pemikiran pasien dari kesembuhan menjadi ke arah penyerahan diri kepada Tuhan dan hubungan dengan orang lain (Superkertia, Astuti, \& Lestari, 2016)

Kualitas hidup merupakan penilaian individu terhadap posisi mereka di dalam kehidupan, dalam konteks budaya dan sistem nilai di mana mereka hidup dalam kaitannya dengan tujuan individu, harapan, standar serta apa yang menjadi perhatian individu (World Health Organization [WHO] Division of Mental Health, 1996). Dengan demikian, kualitas hidup setiap orang dapat berbeda-beda karena kualitas hidup ini bersifat subjektif, yang dapat dilihat dari berbagai aspek yaitu kesehatan fisik, psikologis, hubungan sosial, dan lingkungan (WHO Division of Mental Health, 1996).

Pada aspek psikologis terdapat perasaan positif yang berkaitan dengan adanya rasa syukur yang dimiliki seseorang (Seligman, 2005). Perasaan positif tersebut akan mendorong seseorang untuk melakukan berbagai tindakan yang positif, seperti membangun relasi yang baik dengan masyarakat, memiliki pikiran dan semangat optimisme, memiliki kesehatan rohani yang baik, memiliki keluarga yang harmonis, memiliki semangat saling menolong, hidup rukun dengan tetangga, tahu berterima kasih, mengucap syukur atas apa yang dimiliki, dan menghargai atau menghormati orang lain, unsur-unsur inilah yang membuat seseorang memiliki kebahagiaan sejati (Seligman, 2005). Dengan kata lain, kualitas hidup seseorang akan baik apabila ia bersyukur dengan segala apa yang dimilikinya (Putri, Sukarti, \& Rachmawati, 2016).

Adanya rasa syukur juga diperlukan bagi ODHA perempuan, sebagai bentuk apresiasi terhadap hal-hal yang dimiliki, meskipun dengan kondisinya sebagai penderita HIV/AIDS. Melalui bersyukur, mereka dapat menemukan emosi positif (Emmons \& Mccullough, 2003), meningkatkan harapan (Mccullough, Tsang, \& Emmons, 2004) serta dapat lebih tenang dan tidak panik ketika menghadapi masalah (Makhdlori, 2007).

Syukur dapat muncul melalui proses berpikir dan membiasakan perilaku. Hasil dari proses berpikir yang positif akan menghasilkan emosi yang positif pula. Sebagai bentuk emosi, syukur juga merupakan suatu kondisi yang diperoleh dari dua tahap proses kognitif, yaitu: a) mengenali bahwa seseorang memperoleh hasil yang positif dan b) mengenali adanya sumber eksternal yang berperan hingga hasil positif itu ada (Weiner, dalam Emmons \& Mccullough, 2004). Oleh karena itu, peneliti bermaksud mengembangkan sebuah terapi untuk memunculkan kebersyukuran pada perempuan yang terinfeksi HIV/AIDS melalui metode Cognitive Behavior Therapy (CBT) dengan harapan dapat meningkatkan kualitas hidup mereka. Tujuan dari penelitian ini adalah menguji efektivitas Gratitude Cognitive Behavior Therapy (G-CBT) untuk meningkatkan kualitas hidup perempuan dengan HIV/AIDS.

\section{Metode}

E-JOURNAL GAMAJPP 
Penelitian ini menggunakan variabel tergantung yaitu Kualitas Hidup serta variabel bebas yaitu Gratitude Cognitive Behavior Therapy (G-CBT). Kriteria inklusi partisipan penelitian yaitu: (1) menyandang status HIV dan telah menjalani terapi ARV (antiretroviral) maksimal selama 5 tahun; (2) perempuan dan mendapatkan status HIV dari suaminya; (3) pendidikan minimal SMA; (4) belum pernah mengikuti terapi kebersyukuran sebelumnya dan tidak sedang mengikuti intervensi psikologis; dan (5) bersedia mengikuti penelitian. Partisipan dalam penelitian ini telah menandatangani lembar informed consent sebagai pernyataan kesediaan mengikuti proses penelitian.

Alat ukur yang digunakan dalam penelitian ini adalah Skala Kualitas Hidup dan Skala Bersyukur versi Indonesia. Skala Kualitas Hidup WHOQOL-HIV BREF yang diadaptasi oleh Muhammad, Shatri, Djoerban, dan Abdullah (2017), yaitu versi pendek dari WHOQOL-100. Alat ukur ini disusun berdasarkan enam aspek kualitas hidup menurut WHO (1996) yaitu keadaan fisik, psikologis, tingkat kemandirian, hubungan sosial, hubungan dengan lingkungan, dan spiritualitas, dan telah disesuaikan dengan subjek yang merupakan ODHA sejumlah 29 aitem, dengan menambahkan 2 aitem mengenai persepsi kualitas hidup secara keseluruhan dan persepsi terhadap kesehatan, sehingga totalnya berjumlah 31 aitem dengan koefisien korelasi kuat $(r=0,60-0,79)$, nilai interclass correlation coefficient masingmasing domain 0,41-0,84, dan nilai alpha Cronbach 0,513-0,798. Skala Bersyukur versi Indonesia yang disusun oleh Listiyandini,
Nathania, Syahnia, Sonia, dan Nadya (2015) mengacu pada komponen bersyukur menurut Watkins, et al. (2003) dan Fitzgerald (1998), dan aitem-aitemnya disusun berdasarkan kedua jenis bersyukur menurut Peterson dan Seligman (2004), yaitu bersyukur personal dan transpersonal, dengan nilai alpha (koefisien reliabilitas) sebesar $\alpha=0,8887$ dan nilai corrected item total correlation (Cit) dengan rentang korelasi sebesar $r=0,3-0,6$. Selama proses intervensi, metode wawancara dan observasi juga dilakukan untuk memperoleh data pendukung.

Intervensi diberikan berdasarkan modul G-CBT yang disusun oleh Utami, Shalihah, Adhiningtyas, Rahmah, dan Ningrum (2017) sebagai panduan lengkap untuk melakukan intervensi G-CBT, dengan mengacu pada langkah sederhana dalam menumbuhkan rasa syukur dengan pendekatan kognitif perilaku menurut Miller (dalam Snyder \& Lopez, 2002), yaitu a) mengidentifikasikan pikiran yang salah; b) merumuskan dan mendukung pikiran syukur; c) mengubah pikiran yang salah ke arah pikiran rasa syukur; dan d) mengaplikasikan rasa syukur dalam tindakan batin dan lahiriah.

Sebelum digunakan modul G-CBT telah melalui uji validitas baik validitas isi maupun validitas empiris. Intervensi yang diberikan dalam bentuk psikoedukasi, restrukturisasi kognitif, symbolic modeling, membaca doa syukur, relaksasi, menuliskan jurnal syukur, menuliskan surat terima kasih, dan pemberian tugas rumah. Intervensi dilaksanakan dalam empat kali pertemuan dengan durasi 100-120 menit tiap pertemuan dengan rincian sesi pada tabel 1. 
Tabel 1.

Rincian Sesi G-CBT

\begin{tabular}{|c|c|c|c|}
\hline Pertemuan & Sesi & Rincian Waktu & Kegiatan \\
\hline \multirow[t]{6}{*}{$\begin{array}{c}1 \\
(100 \text { menit })\end{array}$} & 1 & 20 & $\begin{array}{l}\text { Pembukaan, perkenalan dan persetujuan } \\
\text { keikutsertaan }\end{array}$ \\
\hline & 2 & 10 & Harapan terhadap proses terapi \\
\hline & 3 & 30 & Psikoedukasi CBT \\
\hline & 4 & 15 & Pemberian tugas rumah "Kejadian hidup sehari-hari" \\
\hline & 5 & 20 & Relaksasi otot progresif \\
\hline & 6 & 5 & Penutup \\
\hline \multirow{7}{*}{$\begin{array}{c}2 \\
(120 \text { menit })\end{array}$} & 1 & 5 & Pembukaan pertemuan kedua \\
\hline & 2 & 15 & Sharing tugas rumah "Kejadian hidup sehari-hari” \\
\hline & 3 & 40 & $\begin{array}{l}\text { Restrukturisasi kognitif (disertai dengan penayangan } \\
\text { video 1) }\end{array}$ \\
\hline & 4 & 25 & $\begin{array}{l}\text { Penguatan rasa syukur "symbolic modeling" (disertai } \\
\text { dengan penayangan video } 2 \text { ) }\end{array}$ \\
\hline & 5 & 10 & Pemberian tugas rumah “Menghitung Berkah" \\
\hline & 6 & 20 & Relaksasi nafas dan doa \\
\hline & 7 & 5 & Penutup \\
\hline \multirow{6}{*}{$\begin{array}{c}3 \\
(100 \text { menit })\end{array}$} & 1 & 5 & Pembukaan pertemuan ketiga \\
\hline & 2 & 20 & Sharing tugas rumah "Menghitung Berkah" \\
\hline & 3 & 40 & Penguatan rasa syukur : Prososial \\
\hline & 4 & 10 & Pemberian tugas rumah "Menghitung Berkah" \\
\hline & 5 & 20 & Relaksasi nafas dan doa \\
\hline & 6 & 5 & Penutup \\
\hline \multirow{6}{*}{$\begin{array}{c}4 \\
(120 \text { menit) }\end{array}$} & 1 & 5 & Pembukaan pertemuan keempat \\
\hline & 2 & 15 & Sharing tugas rumah "menghitung berkah" \\
\hline & 3 & 50 & Mengekspresikan rasa syukur \\
\hline & 4 & 20 & Evaluasi harapan peserta \\
\hline & 5 & 20 & Evaluasi keseluruhan proses terapi \\
\hline & 6 & 10 & Penutupan \\
\hline
\end{tabular}

Penelitian ini menggunakan desain penelitian desain penelitian single case dengan $n=2$ orang. Desain penelitian yang digunakan adalah desain $A-B-A$. Desain $A$ $B$ - $A$ mengacu pada urutan kondisi dari eksperimen (Barlow \& Hersen, 1987; Sunanto, Takeuchi, \& Nakata, 2005), yang terdiri dari pengulangan pengukuran dalam tiga fase, yatu fase A merupakan pengukuran sebelum dilakukan intervensi, fase $B$ merupakan fase pengulangan pengukuran pada saat diberikan intervensi, dan kembali pada fase A yang merupakan fase pengukuran setelah intervensi (Sunanto et al., 2005). Analisis data dilakukan dengan metode analisis visual, yaitu dengan menggunakan grafik untuk melihat perubahan yang terjadi antar fase. 
Partisipan dalam penelitian ini yaitu LM dan SA. LM mengetahui bahwa dirinya terinfeksi HIV/AIDS yaitu sejak tahun 2013. Saat ini LM tinggal dengan ibu dan anak perempuannya. Anak perempuan LM juga positif HIV/AIDS. Keluarga LM tidak ada yang mengetahui status LM. Perasaan kaget dan sedih saat petugas rumah sakit memberitahukan status LM, namun LM juga bersyukur karena ia mengetahui statusnya saat kondisi fisiknya baik, sehingga ia dapat hidup sehat dan normal seperti orang-orang pada umumnya hingga saat ini. Sedangkan SA mengetahui bahwa dirinya terinfeksi HIV di awal tahun 2017. Saat itu SA dalam keadaan sakit dikarenakan adanya infeksi paru-paru. Dengan kondisi fisik SA yang terusmenerus mengalami penurunan, dokter kemudian menyarankan untuk melakukan VCT (Voluntary Counselling and Testing), dan didapatkan bahwa SA terinfeksi HIV/AIDS. SA memiliki satu anak perempuan yang saat ini berusia 11 tahun namun SA belum memeriksakan keadaan anaknya dikarenakan belum siap jika anaknya positif terinfeksi HIV dan melihat bahwa kondisi anaknya sehat sehingga SA merasa bahwa tes VCT untuk anaknya bukan merupakan hal yang mendesak.

\section{Hasil}

\section{Data kuantitatif}

Gambar 1 menunjukkan bahwa pada partisipan LM menunjukkan peningkatan skor bersyukur dari pretest ke posttest (9 poin), dan meningkat kembali pada saat follow-up (6 poin), sedangkan pada partisipan SA, skor bersyukur mengalami peningkatan dari pretest ke posttest (19 poin), namun sedikit mengalami penurunan skor pada saat follow-up (3 poin). Hal ini menunjukkan bahwa pemberian intervensi G-CBT dapat meningkatkan kualitas hidup kedua partisipan, namun pada saat pengukuran follow-up (satu minggu setelah intervensi dilakukan) menunjukkan hasil yang berbeda, di mana skor bersyukur LM masih mengalami peningkatan sedangkan skor bersyukur SA mengalami sedikit penurunan.

Pada Gambar 2 terlihat bahwa kedua partisipan mengalami peningkatan skor kualitas hidup antara fase pretest, posttest, dan follow-up. Hal ini menunjukkan bahwa

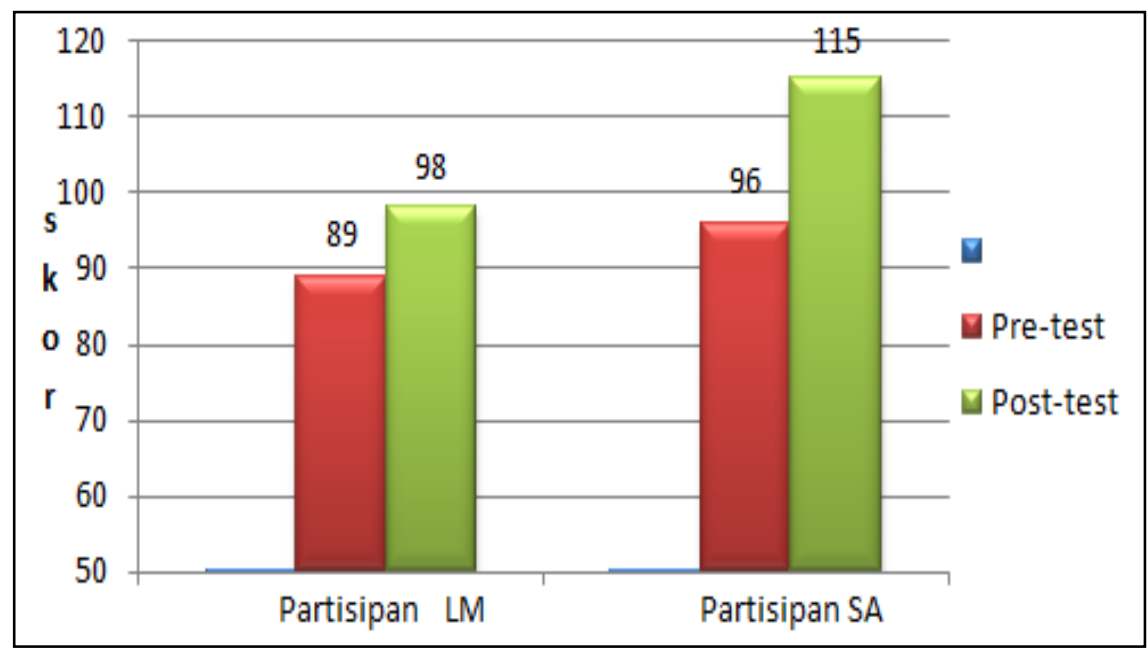

Gambar 1. Skor bersyukur kedua partisipan 


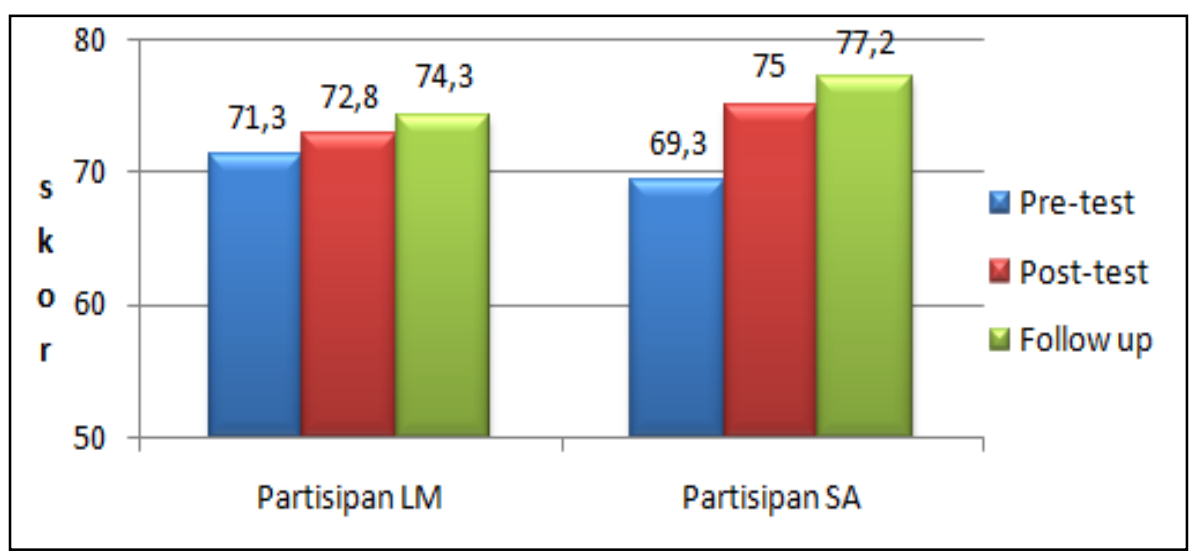

Gambar 2. Skor kualitas hidup kedua partisipan

intervensi berupa G-CBT dapat Lembar Penilaian Diri yang berupa meningkatkan kualitas hidup kedua ceklis suasana hati dan ceklis beban sebagai partisipan, bahkan setelah terapi selesai ODHA dijelaskan pada gambar 3 dan 4 .

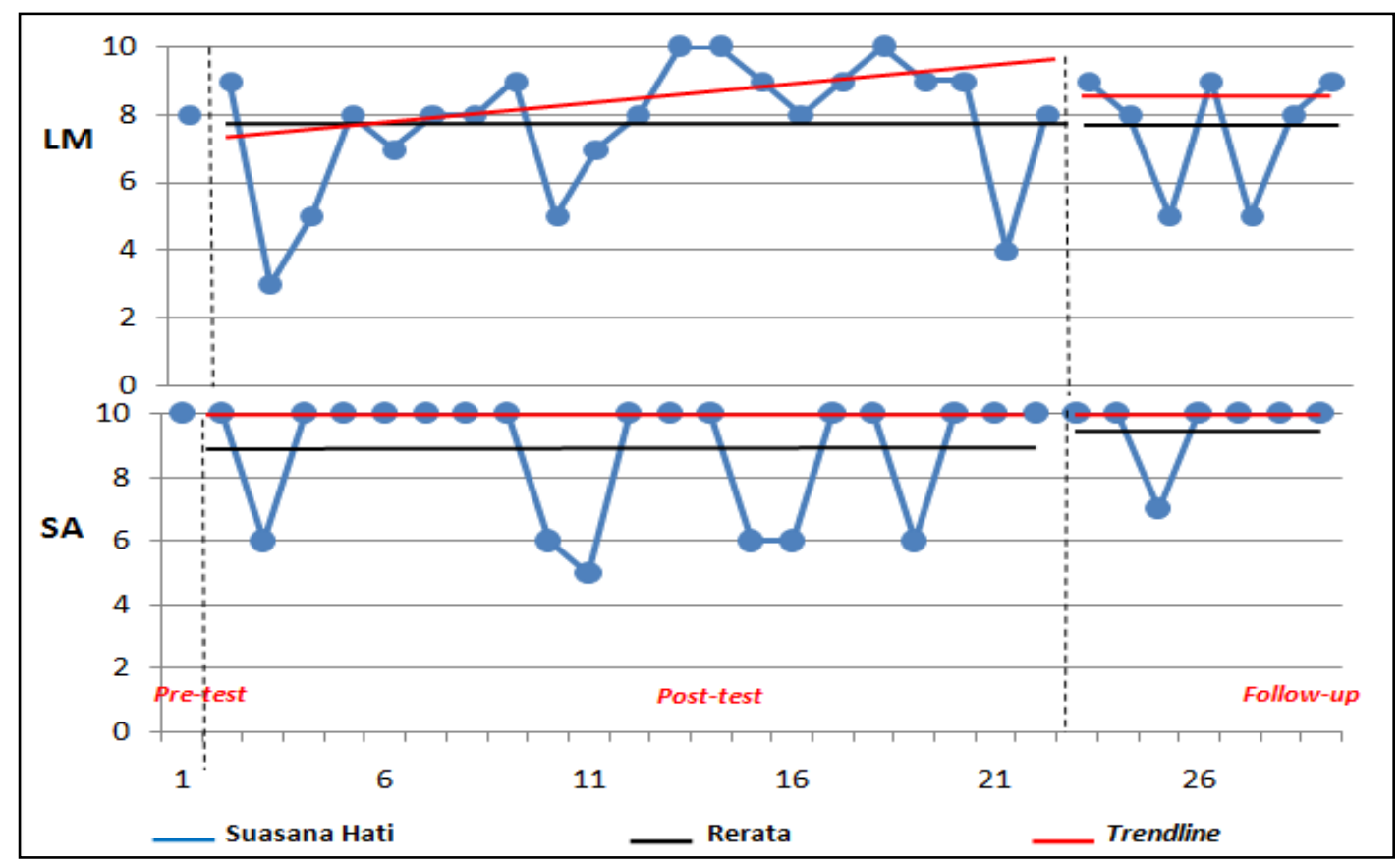

Gambar 3. Skor suasana hati kedua partisipan

diberikan. Pada gambar di atas juga terlihat bahwa saat pengukuran pretest, skor kualitas hidup SA (skor=69,3) lebih rendah dibandingkan skor kualitas hidup LM (skor=71,3), namun pada pengukuran posttest dan follow-up terlihat bahwa skor kualitas hidup SA mengalami peningkatan yang cukup signifikan bahkan melebihi skor kualitas hidup LM.
Pada fase pretest, SA memiliki suasana hati yang lebih positif dibandingkan partisipan LM saat belum diberikan intervensi. Pada fase posttest, data pada LM dan SA dikatakan tidak stabil karena tingkat stabilitas $<80 \%$ yaitu sebesar $27,27 \%$ (LM) dan 68,18\% (SA). LM menunjukkan peningkatan level antara fase pretest dan posttest, namun mengalami penurunan level 


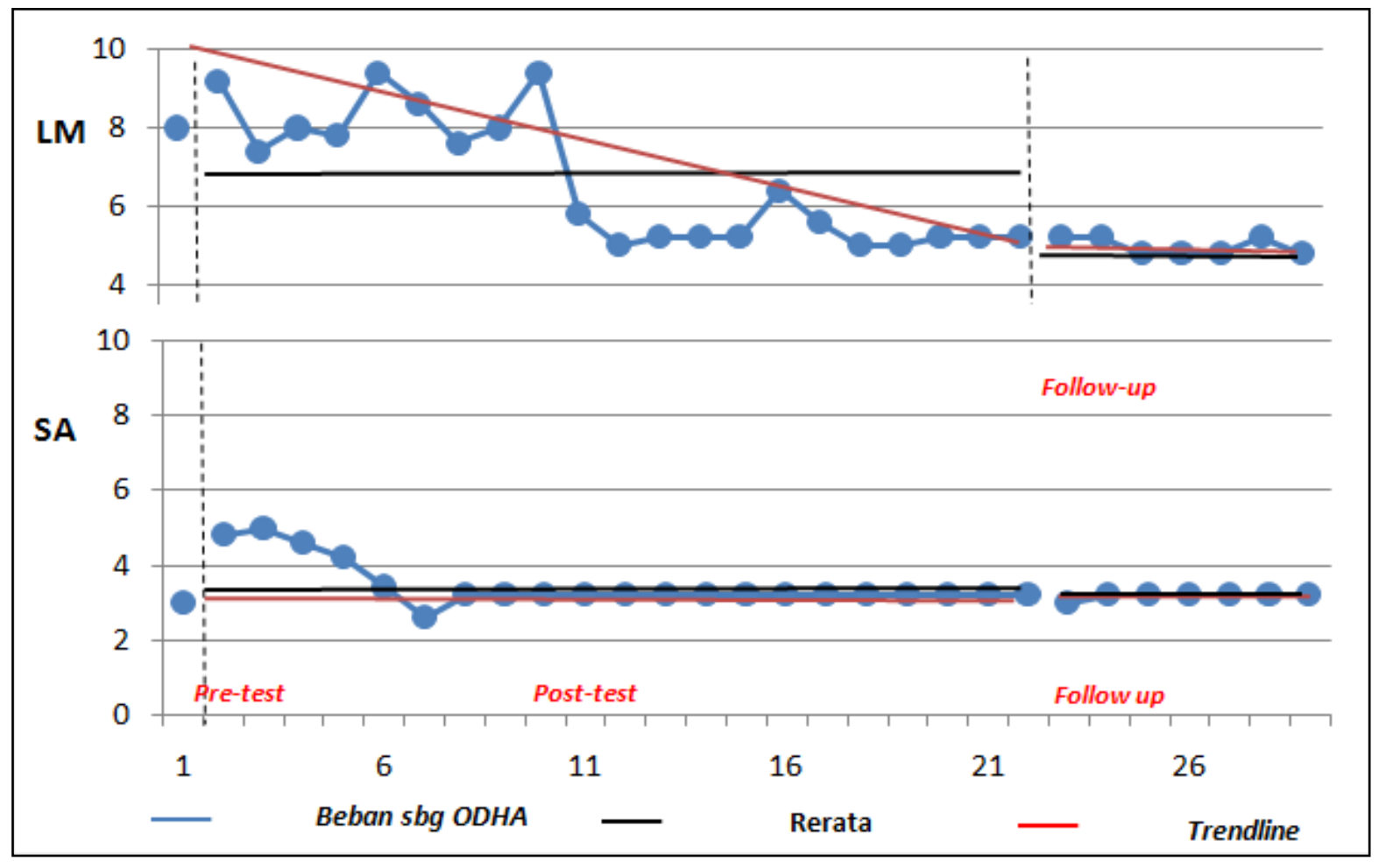

Gambar 4. Skor beban sebagai ODHA kedua partisipan

dalam fase intervensi. Sedangkan partisipan SA menunjukkan tidak adanya perubahan level baik antara fase pretest dan posttest maupun perubahan level dalam fase posttest. Kecenderungan arah grafik (trend) fase posttest, LM menunjukkan arah meningkat, namun SA menunjukkan arah mendatar. Pada fase follow-up, data LM dikatakan tidak stabil yaitu sebesar $28,57 \%$, namun data SA stabil yaitu sebesar $85,71 \%$. LM menunjukkan peningkatan level antara fase posttest dan follow-up namun tidak terjadi perubahan level suasana hati dalam fase follow-up. Sedangkan SA menunjukkan tidak adanya perubahan level baik antara fase posttest dan follow up maupun perbuahan level dalam fase follow-up. Kecenderungan arah grafik (trend) fase follow-up baik kedua partisipan menunjukkan arah mendatar, dengan kata lain intervensi tidak memberikan perubahan kecenderungan suasana hati pada kedua partisipan saat fase follow-up. Selain itu, LM mengalami penurunan rerata skor suasana hati dari fase pretest menuju fase posttest, sedangkan SA mengalami peningkatan rerata skor suasana hati dari fase pretest menuju fase posttest.

Pada fase pretest, LM memiliki beban sebagai ODHA yang lebih dibandingkan SA saat belum diberikan intervensi. Pada fase posttest, data skor beban sebagai ODHA pada kedua partisipan tidak stabil dikarenakan tingkat stabilitas $<80 \%$ yaitu sebesar $13,64 \%$ (LM) dan 72,73\% (SA). LM menunjukkan adanya peningkatan level beban sebagai ODHA antara fase pretest dan posttest, serta penurunan level beban sebagai ODHA dalam fase posttest pada kedua partisipan. Kecenderungan arah grafik (trend) fase posttest, LM menunjukkan arah yang menurun, sedangkan SA 
menunjukkan arah yang mendatar. Pada fase follow-up, data kedua partisipan dapat dikatakan stabil karena tingkat stabilitas sebesar 100\%. LM menunjukkan tidak adanya perubahan penurunan level beban sebagai ODHA dari fase posttest ke followup, kemudian penurunan level beban sebagai ODHA dalam fase follow-up. Sedangkan SA menunjukkan adanya penurunan level dari fase posttest ke follow up, namun terjadinya peningkatan level beban sebagai ODHA pada fase follow up. Kecenderungan arah grafik (trend) fase follow-up LM menunjukkan arah yang menurun, sedangkan pada SA tidak menunjukkan perubahan kecenderungan arah grafik (trend). Rerata skor pada kedua partisipan mengalami penurunan dari fase posttest menuju fase follow-up.

\section{Data deskriptif}

Partisipan LM. Harapan yang diungkapkan LM mengikuti intervensi yaitu agar dapat mengelola emosi dan menerima keadaan sekarang, sehingga dapat hidup ke depan dengan lebih baik dan selalu semangat. LM melihat bahwa keadaannya saat ini merupakan keadaan sehat dan sakit, "sakit kok kelihatan sehat, sehat tapi kok minum obat." Menurut LM, syukur berarti tidak memiliki tuntutan dalam hidupnya. Perasaan sedih dan kaget ketika diberitahu oleh konselor mengenai statusnya. Pikiran utama yang muncul yaitu hidupnya yang tidak lagi lama, namun pikiran tersebut diganti dengan pikiran yang lebih positif, yaitu dengan mengetahui diagnosis lebih awal, ia masih dapat hidup sehat seperti saat ini. LM berusaha menjadikan "status ODHA" sebagai sahabat, karena dimusuhi pun akan tetap ada. Di satu sisi, ia berusaha agar selalu menjaga kesehatannya, di sisi lain ia berusaha agar kondisi tersebut tidak mengganggu aktivitasnya.

Berdasarkan hasil wawancara, lembar kerja, dan tugas rumah dari awal proses hingga akhir, didapatkan bahwa partisipan LM memiliki motivasi yang tinggi untuk mengikuti proses terapi. Hal ini nampak pada keaktifan partisipan dalam mengikuti proses, interaksi yang diberikan baik kepada terapis dan peserta lain, serta komitmen dalam menyelesaikan tugastugas yang diberikan. Keluarga LM tidak ada yang mengetahui status LM sebagai ODHA, termasuk ibu kandung LM. Ibu LM hanya mengetahui jika LM harus mengonsumsi obat secara rutin seumur hidup. Lingkungan sekitar juga tidak ada yang mengetahui statusnya, sehingga ia pun menganggap bahwa ia tidak berbeda dengan teman-temannya. LM tetap beraktivitas dan bersosialisasi seperti layaknya orang pada umumnya.

Perubahan yang dirasakan LM setelah mengikuti rangkaian terapi yaitu ia merasa menjadi lebih sabar dan lebih legowo, serta tidak lagi banyak menuntut diri sendiri. LM menuliskan rasa syukurnya karena diberikan rezeki yang cukup, memiliki ibu yang selalu mendampingi, anak yang selalu patuh untuk terapi ARV, teman-teman yang mendukung, serta bersyukur karena ia mengetahui statusnya sebagai ODHA di saat kondisinya masih sehat, sehingga ia masih dapat hidup seperti orang sehat pada umumnya.

Partisipan SA. Harapan yang diungkapkan SA mengikuti intervensi yaitu untuk menambah pengetahuan, memiliki kemampuan untuk mengelola emosi dan 
menjadi lebih semangat menjalani hidup. SA mengungkapkan bahwa ia sangat terkejut saat mengetahui bahwa dirinya terinfeksi HIV. Saat itu kondisinya dalam keadaan drop di rumah sakit karena penyakit infeksi paru-paru.

Menurut SA, syukur yaitu menikmati dan menerima segala sesuatu dengan sabar dan ikhlas. Kondisi SA saat ini sehat sehingga ia dapat lebih fokus untuk menjaga kesehatannya dan menjalani hidupnya seperti saat kondisinya belum sakit. Orang di sekitar yang mengetahui bahwa SA baru sembuh dari sakit paruparu, memberikan dukungan besar agar SA terus menjaga kesehatannya, salah satunya adalah terus mengingatkan agar SA agar tidak lagi merokok. SA merasa memiliki teman-teman yang peduli dan perhatian pada SA.

Berdasarkan hasil wawancara, lembar kerja, dan tugas rumah dari awal proses hingga akhir, nampak bahwa SA memiliki motivasi yang tinggi untuk mengikuti proses terapi. SA aktif dalam mengikuti diskusi dan berkomitmen menyelesaikan tugas-tugas yang diberikan. SA pun masih melakukan "menghitung berkah" meskipun sesi terapi sudah selesai

Perubahan yang dirasakan SA yaitu ia merasa menjadi lebih sabar dan tidak sombong. SA merasa mendapatkan ilmu dan pengetahuan untuk dapat berubah ke arah yang lebih baik, serta ia menjadi lebih sabar dalam menghadapi suatu masalah. SA mengungkapkan rasa syukur kepada Allah SWT karena selalu diberikan kemudahan, kekuatan dan kesabaran, memiliki keluarga yang sangat peduli, serta tetangga dan sahabat yang baik. SA berdoa agar diberikan umur panjang agar dapat membesarkan anak sampai dewasa dan menjadi orang yang sukses dan berharap agar selalu diberikan kemudahan untuk membahagiakan orang lain.

\section{Diskusi}

Penelitian ini berhasil menguji efektivitas Gratitude Cognitive Behavior Therapy (G-CBT) untuk meningkatkan kualitas hidup perempuan dengan HIV/AIDS. Hal ini ditunjukkan dengan perubahan skor skala kualitas hidup antara sebelum dan sesudah mendapatkan intervensi. Hal ini juga nampak pada peningkatan skor suasana hati dan penurunan skor beban sebagai ODHA pada kedua partisipan.

Status sebagai perempuan dengan HIV/AIDS membawa dampak pada kehidupan partisipan, terlebih karena mereka mendapatkan status tersebut dari suaminya. Perasaan kaget, sedih, tidak percaya, dan ketakutan akan masa depan dialami oleh kedua partisipan. Hal ini sesuai dengan pendapat Fatmawati, Widodo, dan Wakhid (2016) bahwa respons awal ODHA saat mengetahui dirinya positif HIV/AIDS terbagi dalam tiga tahap yaitu tahap kehilangan, perasaan duka cita, dan penolakan terhadap pemberitahuan bahwa telah terdiagnosis HIV/AIDS. Partisipan juga belum siap terbuka dengan statusnya karena kekhawatiran akan stigma dan diskriminasi dari masyarakat yang mungkin mereka dapatkan setelah mengetahui status mereka sebagai ODHA. Kondisi tersebut berdampak pada kualitas hidup yang mereka miliki.

Intervensi G-CBT yang diberikan mengacu pada langkah sederhana dalam menciptakan rasa syukur dengan 
pendekatan kognitif yang dikemukakan oleh Miller (dalam Snyder \& Lopez, 2002), yaitu a) mengidentifikasikan pikiran yang salah; b) merumuskan dan mendukung pikiran syukur; c) mengganti pikiran yang salah ke arah pikiran rasa syukur; dan d) mengaplikasikan rasa syukur dalam tindakan batin dan lahiriah. Sesi-sesi yang diberikan diantaranya adalah psikoeduksi CBT, restrukturisasi kognitif, modeling, menghitung berkah, relaksasi dan doa, yang diberikan dalam empat kali pertemuan.

Selama proses terapi, partisipan diharapkan agar tidak berfokus pada kondisinya sebagai ODHA, melainkan halhal yang masih dapat mereka lakukan dengan kondisi saat ini. Baik LM maupun SA memahami bahwa ia masih bisa bekerja, jalan-jalan, berkumpul dengan keluarga dan teman-temannya meskipun dengan statusnya sebagai ODHA. Fokus kedua partisipan saat ini yaitu menjaga kesehatan dan membesarkan anak hingga menjadi orang yang sukses. Partisipan diajak untuk mengekspresikan rasa syukur dengan menuliskan surat syukur kemudian membacakannya, serta mensyukuri hal-hal besar yang ia terima. Rasa syukur tersebut dapat disampaikan kepada Tuhan, orang lain, maupun lingkungan. Melalui doa syukur, partisipan diajak untuk mengingat berkah yang telah diterima hingga saat ini (Emmons \& Hill, 2001) .

Kedua partisipan menuliskan secara rutin minimal tiga keberkahan yang diterima dalam tugas menghitung berkah. Hal ini diantaranya bertujuan untuk memunculkan emosi positif dan menguatkan hubungan interpersonal (Emmons \& Mccullough, 2003). Bahkan setelah intervensi selesai diberikan, kedua partisipan masih melanjutkan pengisian tugas "menghitung berkah". Hal ini membantu partisipan untuk terus dapat mensyukuri hal-hal sekecil mungkin. Hal ini sesuai dengan penelitian Emmons dan Mccullough (2003) yang menyatakan bahwa individu yang menuliskan jurnal syukur secara teratur dilaporkan memiliki lebih sedikit gejala penyakit fisik, merasa lebih baik mengenai hidupnya secara keseluruhan dan lebih optimis mengenai kehidupan.

Setelah empat pertemuan dilaksanakan, partisipan diberikan kembali skala kualitas hidup. Terlihat bahwa sesudah mendapatkan intervensi GCBT, kualitas hidup kedua partisipan mengalami peningkatan. Dengan demikian dapat dikatakan bahwa intervensi G-CBT dapat meningkatkan kualitas hidup partisipan sebagai perempuan dengan HIV/AIDS.

Hasil penelitian ini mendukung hasil penelitian yang dilakukan oleh Putri, Sukarti, \& Rachmawati (2016) dengan partisipan guru inklusi, yang menunjukkan bahwa pelatihan kebersyukuran dapat meningkatkan kualitas hidup. Peningkatan skor kualitas hidup didukung dengan peningkatan rerata skor suasana hati kedua partisipan yang diukur dengan ceklis suasana hati (mood scale) selama 29 hari berturut-turut. Pada LM, skor suasana hati mengalami penurunan dari pretest menjadi posttest, berbeda dengan SA yang mengalami peningkatan skor suasana hati. Jika dilihat dengan lebih detail, sebagian besar skor yang diberikan oleh SA pada ceklis suasana hati adalah skor 10. Temuan ini senada dengan penelitian Mccullough, Tsang, dan Emmons (2004) bahwa salah 
satu emosi positif yang muncul karena rasa syukur yaitu suasana hati yang lebih baik. Emmons dan Mccullough (2003) juga mengungkapkan bahwa adanya rasa syukur dapat memunculkan emosi positif dan menurunkan emosi negatif.

Pada skor beban sebagai ODHA, rerata skor kedua partisipan mengalami penurunan pada saat posttest. Hal ini sejalan dengan penelitian yang dilakukan oleh Cahyono (2014) yang menunjukkan bahwa Pelatihan Kebersyukuran dapat menurunkan tingkat stres apabila didukung oleh proses kognitif yang memadai karena di dalam syukur terdapat 2 aspek yang utama yaitu berpikir positif untuk melihat nilai tambah yang ada pada suatu situasi atau kondisi yang sedang dihadapi seseorang dan melakukan tindakan nyata sebagai suatu wujud rasa terima kasih atas pemberian tersebut dengan diiringi keyakinan secara religius. Weiten dan Llyof (dalam Hidayanti, 2013) mengatakan bahwa koping merupakan upaya-upaya untuk mengatasi, mengurangi, atau menerima beban perasaan yang tercipta karena stres. Perempuan dengan HIV/AIDS yang mampu mengembangkan strategi koping yang positif dapat terus bertahan dengan penyakit dan segala konsekuensi hidup yang dijalani (Hidayanti, 2013), dan syukur merupakan salah satu strategi koping yang positif.

Pada pengukuran yang dilakukan pada satu minggu setelah intervensi selesai diberikan, terlihat bahwa skor kualitas hidup kedua partisipan mengalami peningkatan. Dengan kata lain, intervensi G-CBT yang diberikan kepada partisipan masih dirasakan dampaknya meskipun intervensi telah selesai diberikan. Hal ini senada dengan penelitian sebelumnya oleh Cahyandari, Nashori, dan Sulistyarini (2015) pada pasien penyakit paru obstruktif kronik (PPOK) yang menunjukkan bahwa Pelatihan Kebersyukuran dapat meningkatkan kualitas hidup hingga tahap tindak lanjut (dua minggu setelah pelatihan berakhir).

Peningkatan kualitas hidup pada kedua partisipan didukung dengan peningkatan rasa syukur yang mereka miliki. Baik pada LM maupun SA, menunjukkan bahwa rasa syukur yang diukur dengan skala bersyukur versi Indonesia mengalami peningkatan dari pretest ke posttest. Skor tersebut juga terus mengalami peningkatan pada pengukuran saat follow up. Kedua partisipan mengalami peningkatan skor pada saat pengukuran posttest dan follow-up.

Keterbatasan utama dalam penelitian ini yaitu terletak pada validitas eksternalnya, dan dalam penelitian single case, hasil penelitian tidak dapat digeneralisasikan. Meskipun intervensi terbukti efektif untuk satu individu, namun belum tentu efektif untuk individu lain, dan efek intervensi mungkin tidak akan sama ketika diberikan di kemudian hari pada individu yang sama (Nock et al., 2007). Keterbatasan lain terletak pada validitas internal seperti social desirability dan testing effect. Pada pengukuran yang dilakukan dengan self report, social desirability bertanggung jawab atas sebagian besar varians data yang dikumpulkan. Adapun testing effect merupakan efek yang dihasilkan oleh pengukuran variabel tergantung. Pada penelitian ini pengukuran dilakukan sebanyak tiga kali pada variabel 
tergantung, dan pengisian lembar penilaian diri selama 29 hari berturut-turut.

Selain itu, keterbatasan dalam penelitian ini adalah kesulitan dalam mencari partisipan penelitian. Dari 19 calon partisipan yang mengisi skala kualitas hidup dan skala bersyukur pada saat screening, hanya didapatkan dua orang partisipan yang memenuhi kriteria dan berkomitmen mengikuti penelitian hingga selesai. Hal ini dikarenakan kriteria inklusi yang sempit dan pelaksanaan penelitian yang memakan waktu cukup lama yaitu lebih kurang selama 5 minggu (dari mulai pretest hingga follow up).

\section{Kesimpulan}

Hasil penelitian menunjukkan bahwa Gratitude Cognitive Behavior Therapy dapat meningkatkan kualitas hidup pada perempuan dengan HIV/AIDS. Efek dari GCBT yang diberikan terbukti dapat bertahan paling tidak selama satu minggu. Hasil tersebut didukung dengan meningkatnya suasana hati dan menurunnya beban sebagai ODHA pada partisipan. Selain itu, hasil cek manipulasi menunjukkan bahwa intervensi telah berjalan sesuai dengan tujuan peneliti. Kedua partisipan merasakan manfaat mengikuti G-CBT terutama dengan adanya tugas menghitung berkah. Dibandingkan dengan sebelum intervensi, mereka dapat lebih mengendalikan emosi, dapat lebih bersyukur, dan berpikir dengan lebih positif.

Saran

Berdasarkan hasil penelitian, berikut beberapa saran yang dapat diberikan : (1) partisipan penelitian, diharapkan dapat terus mengaplikasikan keterampilan yang telah dipelajari seperti menghitung berkah (gratitude journal), menuliskan surat syukur, dan relaksasi; (2) penelitian selanjutnya dapat menguji efektivitas modul ini dengan cakupan partisipan yang lebih luas, seperti jenis kelamin ataupun faktor risiko penularan lainnya seperti penggunaan narkoba suntik atau hubungan seksual dengan sesama jenis. Kesulitan dalam mencari partisipan penelitian dapat diatasi dengan melakukan screening awal dengan partisipan yang lebih banyak dan memperluas kriteria inklusi partisipan penelitian. Penelitian selanjutnya juga diharapkan dapat lebih mengontrol validitas internal seperti efek testing atau social desirability.

\section{Kepustakaan}

Azza, A. (2010). Beban perempuan penderita HIV/AIDS dalam perspektif gender. Jurnal Ners, 5(2), 118-126.

Barboza, R. D. A., Ramos, T. M. B., De Veras, D. C., Rego, R. B. do, Silva, C. S. da, Costa, M. A. J., ... Silva, E. H. (2017). Quality of life of women living with HIV/AIDS. International Archives of Medicine, 10(120), 1-10.

Barlow, D.H. \& Hersen, M. (1987). Singlecase experimental design: Strategies studying behavior change (Edisi kedua). New York: Pergamon Press.

Brenda \& Wet. (2010). HIVIAIDS related communication, hearing, and swallowing disorders. Plural Publishing.

Cahyandari, P. R., Nashori, F., \& Sulistyarini, I. (2015). Efektivitas pelatihan kebersyukuran untuk 
meningkatkan kualitas hidup pasien penyakit paru obstruktif kronik (PPOK). Jurnal Intervensi Psikologi, $7(1), \quad 1-14 . \quad$ doi: 10.20885/intervensipsikologi.vol7.iss1. $\underline{\operatorname{art1}}$

Cahyono, E. W. (2014). Pelatihan gratitude (bersyukur) untuk penurunan stres kerja karyawan di PT.X. Calyptra, 3(1), $1-15$.

Djoerban, Z. (1999). Membidik AIDS, ikhtiar memahami HIV dan ODHA. Yogyakarta: Galang Press.

Emmons, R. A., \& Hill, J. (2001). Words of gratitude: For mind, body and soul. USA: Templeton Foundation Press.

Emmons, R. A., \& Mccullough, M. E. (2003). Counting blessings versus burdens: An experimental investigation of gratitude and subjective well-being in daily life. Journal of Personality and Social Psychology, 84(2), 377-389. doi: 10.1037/0022-3514.84.2.377

Emmons, R. A., \& Mccullough, M. E. (2004). The psychology of gratitude. United States: Oxford University Press.

Fatmawati, F., Widodo, G. G., \& Wakhid, A. (2016). Kualitas hidup orang dengan HIVIAIDS (ODHA) berdasarkan quality of life di Kota Semarang. Semarang: Stikes Ngudo Waluyo.

Fitzgerald, P (1998). Gratitude and justice. Ethics, 109, 119-153. doi: $\underline{10.1086 / 233876}$

Hardiansyah, Amiruddin, R., \& Arsyad, D. S. (2014). Kualitas hidup orang dengan HIV dan AIDS di Kota Makassar. Makassar: Universitas Hasanuddin. Hidayanti, A. (2013). Strategi coping stress perempuan dengan HIV/AIDS.
Sawwa: Jurnal Studi Gender, 9(1), 89106.

Kementerian Kesehatan Republik Indonesia. (2018). Infodatin: Situasi umum HIV \& AIDS dan tes HIV. Jakarta: Kementerian Kesehatan Republik Indonesia.

Listiyandini, R. A., Nathania, A., Syahniar, D., Sonia, L., Nadya, R., Psikologi, F., ... Indonesia, U. (2015). Mengukur rasa syukur: Pengembangan model. Jurnal Psikologi Ulayat, 2(2), 473-496. doi: 10.24854/jpu22015-41

Makhdlori, M. (2007). Bersyukurlah maka engkau akan kaya. Yogyakarta: Diva Press.

Mccullough, M. E., Tsang, J., \& Emmons, R. A. (2004). Gratitude in intermediate affective terrain: Links of grateful moods to individual differences and daily emotional experience. Journal of Personality and Social Psychology, 86(2), 295-309. doi: 10.1037/00223514.86.2.295

Muhammad, N. N., Shatri, H., Djoerban, Z., \& Abdullah, M. (2017). Uji kesahihan dan keandalan kuesioner World Health Organization Quality of LifeHIV Bref dalam Bahasa Indonesia untuk mengukur kualitas hidup pasien HIV/AIDS. Jurnal Penyakit Dalam Indonesia, 4(3), 112-118. doi: 10.7454/jpdi.v4i3.137

Nock, M. K., Michel, B. D., \& Photos, V. I. (2007). Small samples and N-of-1 designs. In D. McKay (Ed.), Handbook of Research Methods in Abnormal and Clinical Psychology (hal. 337-350). Thousand Oaks: SAGE Publications, Inc. 
Peterson, C., \& Seligman, M. E. P. (2004). Character strengths and virtues: $A$ Handbook and classification. New York: Oxford University Press.

Putri, D. A., Sukarti, \& Rachmawati, M. A. (2016). Pelatihan kebersyukuran untuk meningkatkan kualitas hidup guru sekolah inklusi. Jurnal Intervensi Psikologi, 8(1), 21-40. doi: 10.20885/intervensipsikologi.vol8.iss1. art2

Rachmawati, S. (2013). Kualitas hidup orang dengan HIV/AIDS yang mengikuti terapi antiretroviral. Jurnal Sains dan Praktik Psikologi, 1(1), 48-62.

Safarina, L. (2012). Pengalaman hidup perempuan di Kota Cimahi (Studi fenomenologi). Diakses melalui http://stikesayani.ac.id/publikasi/ejour nal/files/2012/201212/201212-003.pdf

Seligman, M. E. P. (2005). Authentic happines: Menciptakan kebahagiaan dengan psikologi positif. Bandung: Mizan Pustaka.

Snyder, C. R., \& Lopez, S. J. (2002). Handbook of positive psychology. New York: Oxford University Press.

Sunanto, J., Takeuchi, K., \& Nakata, H. (2005). Pengantar penelitian dengan subyek tunggal. Jepang: CRICED.

Spiritia. (2014). Infeksi HIV primer. Diakses melalui

http://spiritia.or.id/informasi/detail/4

Superkertia, I. G. M. E., Astuti, I. W., \& Lestari, M. P. L. (2016). Hubungan antara tingkat spiritualitas dengan tingkat kualitas hidup pada pasien HIV/AIDS di Yayasan Spirit Paramacitta Denpasar. Coping: Community of Publishing in Nursing, $4(1), 49-53$.
Utami, M.S., Shalihah, M., Adhiningtyas, N.P., Rahmah, S., \& Ningrum, W.K. (2017). Gratitude-cognitive behavior therapy (G-CBT) untuk menurunkan stres pada mahasiswa (Manuskrip tidak dipublikasikan). Yogyakarta: Universitas Gadjah Mada.

Watkins, P. C., Woodward, K., Stone, T., \& Kolts, R. L. (2003). Gratitude and happiness: Development of a measure of gratitude and subjective well-being. Social Behavior and Personality, 31(5), 431-452.

doi:

10.2224/sbp.2003.31.5.431

World Health Organization Division of Mental Health. (1996). WHOQOL-Bref: Introduction, administration, scoring and generic version of the assessment. Diakses melalui https://apps.who.int/iris/handle/10665 $\lcm{63529}$

Yulianti, A. P. (2013). Kerentanan perempuan terhadap penularan HIV \& AIDS : studi pada ibu rumah tangga pengidap HIV/AIDS di Kabupaten Pati, Jawa Tengah. Palastren, 6(1), 185-200. 